\title{
Extracavitary Primary Effusion Lymphoma
}

National Cancer Institute

\section{Source}

National Cancer Institute. Extracavitary Primary Effusion Lymphoma. NCI Thesaurus.

Code C150406.

A rare $\mathrm{HHV8-positive} \mathrm{B-cell} \mathrm{lymphoma} \mathrm{indisting} \mathrm{uishable} \mathrm{from} \mathrm{primary} \mathrm{effusion}$

lymphoma presenting as solid tumor mass. (WHO 2017) 